Check for updates

Cite this: RSC Adv., 2017, 7, 44547

\title{
Facet-dependent magnesiation behavior of $\alpha-S n$ as an anode for magnesium ion batteries
}

\begin{abstract}
Wei Jin and Zhiguo Wang (D) *
The adsorption and magnesiation behavior of $\mathrm{Mg}$ onto $\alpha$-Sn and $\mathrm{Mg}_{2} \mathrm{Sn}$ through (100), (110) and (111) surfaces were investigated by using first-principles calculations. It was found that the $\mathrm{Mg}$ atom prefers to be adsorbed on the surface rather than diffuse into the sub-surface of Sn. The diffusion energy barrier is higher for Mg diffusing from the surface to the subsurface compared with the internal diffusion. Mg diffuses much faster along the $<100>$ direction than along the $<110>$ and $<111>$ directions. The diffusion process from the surface to the subsurface is a rate-limiting step for $\mathrm{Mg}$ intercalation into $\mathrm{Sn}$. The surface magnesiation is also a rate-limiting step for $\mathrm{Mg}$ intercalation into $\mathrm{Mg}_{2} \mathrm{Sn}$ though (100) and (110) surfaces, whereas the surface magnesiation of the $\mathrm{Mg}_{2} \mathrm{Sn}$ (111) surface is easier than the (100) and (110) surfaces. Surface modification is necessary to improve the magnesiation behavior of $\mathrm{Sn}$ as an anode for MIBs, especially when the anode materials are reduced to the nanoscale.
\end{abstract}

Received 18th July 2017

Accepted 11th September 2017

DOI: 10.1039/c7ra07899d

rsc.li/rsc-advances

atom into the surface and subsurface layers of Ge and Sn using DFT calculations. Their simulation results suggested that the rate-limiting step in Sn was the subsurface diffusion in both the $\operatorname{Sn}(100)$ and $\operatorname{Sn}(111)$ surfaces. They also found that Li diffused faster by at least two orders of magnitude along the [100] crystal orientation than along the [111] crystal orientation..$^{17}$

Although Sn has been studied as anode for MIBs, ${ }^{12,13}$ yet few studies have been performed on $\mathrm{Mg}$ magnesiation into $\mathrm{Sn}$ surfaces. As the surface lithiation is the rate-limiting step when Sn used as anode for lithium ion batteries, in this work we studied $\mathrm{Mg}$ magnesiation into $\mathrm{Sn}(100), \operatorname{Sn}(110), \operatorname{Sn}(111)$, $\mathrm{Mg}_{2} \mathrm{Sn}(100), \mathrm{Mg}_{2} \mathrm{Sn}(110)$, and $\mathrm{Mg}_{2} \mathrm{Sn}(111)$ surfaces using DFT calculations to understand the electrochemical behavior of the $\mathrm{Sn}$ as the anode materials for the MIBs. conventional electrolyte. It was found that the $\mathrm{Sn}$ can endure much higher strain and capacity retention by reducing their size to nanoscale. ${ }^{\mathbf{1 4 , 1 5}}$ Many studies had been focus on the understanding of $\mathrm{Mg}$ diffusion process within the $\mathrm{Sn}$ anodes. ${ }^{\mathbf{1 3 , 1 6}}$ However, $\mathrm{Mg}$ ions transport in the Sn surface exposed to the electrolyte is of great importance as the first step of the $\mathrm{Mg}$ insertion into the anode. The surface magnesiation can hardly be observed by an experimental setup; density functional theory (DFT) calculations can provide an atomistic understanding of the magnesiation procedure and predict the electrochemical properties of surface magnesiation. ${ }^{17,18}$ Kaghazchi et al. ${ }^{18}$ have studied the lithiation of $\mathrm{Li}$ into $\operatorname{Sn}(100)$ surface and found that Li was more stable at interstitial sites between the topmost surface-layers of $\operatorname{Sn}(100)$ than at the surface sites and bulk sites using DFT. Jung et al. ${ }^{19}$ investigated the intercalation of a $\mathrm{Li}$

School of Physical Electronics, Center for Public Security Technology Research, University of Electronic Science and Technology of China, Chengdu, 610054, P. R. China.E-mail: zgwang@uestc.edu.cn

\section{Computational methods}

All the calculations were carried out using the DFT as implemented within the SIESTA code. ${ }^{20}$ The generalized gradient approximation (GGA) with Perdew-Burke-Ernzerhof (PBE) function was used to describe the electron exchange-correlation term. ${ }^{21,22}$ The interactions between the core and valence electrons were described by nonlocal norm-conserving pseudopotentials. $^{23}$ The valence electron wave functions were expanded using double- $\zeta$ basis functions. For calculating the self-consistent Hamiltonian matrix elements, the charge density was projected on a real space grid with a cutoff of 150 Ry. The calculated bulk bond length of Sn-Sn was $2.89 \AA$ for $\alpha$-Sn, which was in good agreement with experimental value of $2.81 \AA ̊$ (ref. 24) and previous DFT calculated value of $2.88 \AA{ }^{19}$

The surfaces of $\alpha$-Sn were modeled using asymmetric slabs which composed of fourteen layers Sn atoms. One side of the 
slabs was saturated with hydrogen atoms. The bottom four Sn atomic layers and the hydrogen layer were fixed to model the bulk $\mathrm{Sn}$, and the remaining layers and the adsorbed $\mathrm{Mg}$ atom were allowed to relax freely. The slab thickness are 22.4, 31.8, and $25.5 \AA$ for slabs with (100), (110) and (111) surfaces, respectively, which has been previously tested to be reliable ${ }^{25}$ for investigating adsorption and diffusion for $\mathrm{Li}$ in $\mathrm{Sn},{ }^{18,19} \mathrm{Ge}^{19}$ and $\mathrm{Si}^{17,26}$ surfaces. The surfaces of the $\mathrm{Mg}_{2} \mathrm{Sn}$ were modeled with slab thickness of 22.8, 32.3, and 25.3 A for (100), (110) and (111) facets, respectively. The use of such asymmetric slabs was corrected by the dipole correction scheme of Neugebauer and Scheffler. ${ }^{27}$ A vacuum spacing between the slabs and its image exceeds $20 \AA$ to avoid the periodic image interactions.

Because the unreconstructed $\operatorname{Sn}(100)-(1 \times 1)$ surface has been proved to be unstable, ${ }^{18}$ we used the $(4 \times 2)$ surface unit cell to simulate the $\operatorname{Sn}(100)$ surface which is the ground state of $\mathrm{Sn}(100)$ consisting of buckled rows of Sn dimers, as shown in Fig. 1a. The relaxed $\operatorname{Sn}(110)$ and $\operatorname{Sn}(111)$ surfaces were shown in Fig. $1 \mathrm{~b}$ and c, respectively. The adsorption energy $\left(E_{\mathrm{ad}}\right)$ of $\mathrm{Mg}$ on Sn surfaces was calculated using eqn (1):

$$
E_{\mathrm{ad}}=\frac{E_{\mathrm{Mg} / \mathrm{slab}}-n E_{\mathrm{Mg}}-E_{\mathrm{slab}}}{n}
$$

where $E_{\mathrm{Mg} / \mathrm{slab}}$ and $E_{\text {slab }}$ are the total energies of Sn slab with and without the $\mathrm{Mg}$ atom adsorption, respectively. $E_{\mathrm{Mg}}$ is the energy of a free $\mathrm{Mg}$ atom, and $n$ is the number of adsorbed $\mathrm{Mg}$ atoms.

\section{Results and discussion}

\subsection{Adsorption and magnesiation $\mathrm{Mg}$ into $\mathrm{Sn}(100)$ surface}

There are four possible adsorption sites for $\mathrm{Mg}$ on $\mathrm{Sn}(100)$-c $(4 \times 2)$ surface due to the symmetry of the geometric structure, shown in Fig. 1a. The H1 is the pedestal site, and B is the dimer bridge site. The cave (H2) site is located at the bottom of the trough and the valley bridge (T) site is on top of the thirdlayer $\mathrm{Sn}$ atom. ${ }^{28}$ According to the definition of adsorption energy in eqn (1), a negative value means a favorable exothermic reaction between the substrate and $\mathrm{Mg}$. The larger the negative value is, the more favorable of the reactions is. The calculated adsorption energies are listed in Table 1. Among all the adsorption sites, the $\mathrm{H} 2$ site is with the largest negative values, which means that the $\mathrm{Mg}$ prefers to be adsorbed at the $\mathrm{H} 2$ site. The $\mathrm{H} 1$ site is less stable than $\mathrm{H} 2$ site by $0.15 \mathrm{eV}$. The geometry optimizations for $\mathrm{Mg}$ adsorption starting from the B site eventually led to the stable $\mathrm{H} 1$ site. Besides, the $\mathrm{T}$ site is with adsorption energy of $-0.53 \mathrm{eV}$, which is less stable adsorption site for $\mathrm{Mg}$.

The energetically favorable adsorption site, $\mathrm{H} 2$, on $\operatorname{Sn}(100)$ was taken to be the initial site for the magnesiation of $\mathrm{Mg}$ into the Sn crystal through $\operatorname{Sn}(100)$ surface. Based on the adsorption energies listed in Table 1, the diffusion pathway $\mathrm{H} 2 \rightarrow \mathrm{S} 1 \rightarrow$ $\mathrm{S} 2 \rightarrow \mathrm{S} 3 \rightarrow \mathrm{S} 4 \rightarrow \mathrm{S} 5$ was investigated, which is the energetic favorable diffusion pathway for $\mathrm{Mg}$ magnesiation into $\mathrm{Sn}$ through (100) surface. A similar diffusion behavior was found for the lithiation of $\mathrm{Si}(100),{ }^{17,26} \mathrm{Sn}(100)^{18}$ and Ge $(100)^{19}$ surfaces. We used $\operatorname{Sn}(n=1,2,3,4,5)$ to represent the adsorption sites of $\mathrm{Mg}$ at the $n$th layer of Sn away from the surface. As shown in Fig. 2, the $\mathrm{Mg}$ atom is energetically favorable at the tetrahedral site with the four nearest $\mathrm{Sn}$ atoms. $\mathrm{Mg}$ diffuses from on stable tetrahedral site to a nearest one by passing through a hexagonal site. The diffusion energy profile of $\mathrm{Mg}$ through the pathway $\mathrm{H} 2 \rightarrow \mathrm{S} 1 \rightarrow \mathrm{S} 2 \rightarrow \mathrm{S} 3 \rightarrow \mathrm{S} 4 \rightarrow \mathrm{S} 5$ was shown in Fig. 2 . The energy for $\mathrm{Mg}$ at the $\mathrm{H} 2$ and $\mathrm{Sn}$ site increases as the $\mathrm{Mg}$ magnesiation into the inside of $\mathrm{Sn}$. The closer the adsorbed site to the $\operatorname{Sn}(100)$ surface, the lower the energy is, which is due to more effective stress release near the surface. ${ }^{29}$ The diffusion energy barriers for $\mathrm{Mg}$ magnesiation into Sn through the (100) surface can be read from Fig. 2. The diffusion energy barrier is $1.05 \mathrm{eV}$ for $\mathrm{Mg}$ diffuses from $\mathrm{H} 2$ to S1 site, and which are 0.84, 0.66, 0.65 and $0.63 \mathrm{eV}$ for $\mathrm{Mg}$ diffuses to S2, S3, S4 and S5, respectively. It is can be seen that the surface magnesiation of $\mathrm{Mg}$ is with the highest diffusion energy barrier, whereas the inside diffusion with small one, which also shows less dependence on the position. So the surface magnesiation ( $\mathrm{H} 2 \rightarrow \mathrm{S} 1$ ) becomes the rate-limiting step during $\mathrm{Mg}$ intercalated into Sn through the (100) surface.

\subsection{Adsorption and magnesiation $\mathrm{Mg}$ into $\mathrm{Sn}(110)$ surface}

Three adsorption sites, i.e. $\mathrm{H}, \mathrm{B}$ and $\mathrm{T}$ sites were considered for the adsorption of $\mathrm{Mg}$ on $\mathrm{Sn}(110)$ surface, as shown in Fig. $1 \mathrm{~b}$. (a) $\operatorname{Sn}(100)$
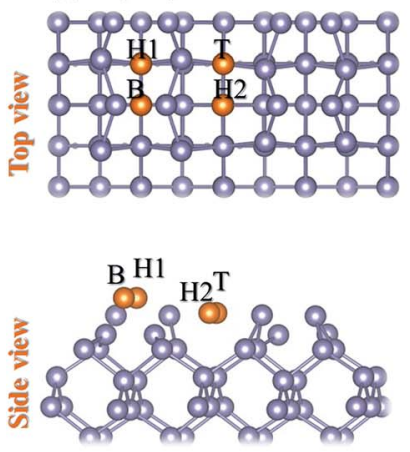

(b) $\operatorname{Sn}(110)$
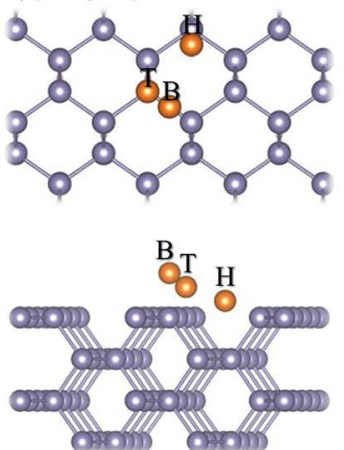

(c) $\operatorname{Sn}(111)$
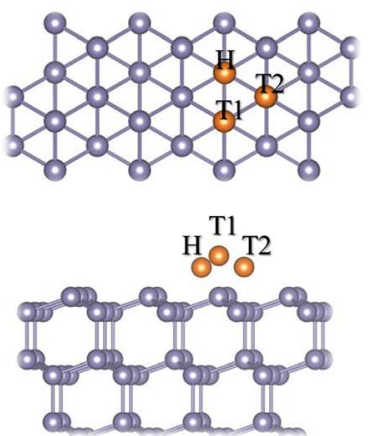

Fig. 1 Surface geometries and Mg adsorption sites of (a) Sn(100), (b) Sn(110) and (c) Sn(111), respectively. The orange balls represent the different adsorption sites (hollow sites, bridge sites and top sites are indicated by H, B, and T, respectively) on these surfaces, and gray balls represent $\mathrm{Sn}$ atoms. 
Table 1 The adsorption energy of Mg atom on the Sn(100), Sn(110) and Sn(111) surfaces

\begin{tabular}{|c|c|c|c|c|c|}
\hline \multicolumn{2}{|l|}{$\mathrm{Sn}(100)$} & \multicolumn{2}{|l|}{$\operatorname{Sn}(110)$} & \multicolumn{2}{|l|}{$\operatorname{Sn}(111)$} \\
\hline $\begin{array}{l}\text { Adsorption } \\
\text { site }\end{array}$ & $E_{\text {ad }} / \mathrm{eV}$ & $\begin{array}{l}\text { Adsorption } \\
\text { site }\end{array}$ & $E_{\mathrm{ad}} / \mathrm{eV}$ & $\begin{array}{l}\text { Adsorption } \\
\text { site }\end{array}$ & $E_{\text {ad }} / \mathrm{eV}$ \\
\hline H1 & -1.20 & $\mathrm{H}$ & -4.39 & $\mathrm{H}$ & -1.62 \\
\hline $\mathrm{H} 2$ & -1.35 & B & -1.39 & $\mathrm{~T} 1$ & -0.81 \\
\hline B & -1.20 & $\mathrm{~T}$ & -1.39 & $\mathrm{~T} 2$ & -1.46 \\
\hline $\mathrm{T}$ & -0.53 & & & & \\
\hline
\end{tabular}

The $\mathrm{H}$ site is above the center of triangle structure composed of three $\mathrm{Sn}$ atoms on the surface, B site is on top of a Sn-Sn bond, and $\mathrm{T}$ site is above the top of one $\mathrm{Sn}$ atom. The calculated adsorption energies were listed in Table 1 . The $\mathrm{H}$ site is the energetically stable one with an adsorption energy of $-4.39 \mathrm{eV}$. It was found that the $\mathrm{T}$ site is not stable for $\mathrm{Mg}$ adsorption, and the $\mathrm{Mg}$ atom moves from the $\mathrm{T}$ site to the adjacent $\mathrm{H}$ site after relaxation. The adsorption energy is $-1.39 \mathrm{eV}$ for the $\mathrm{Mg}$ adsorbed at B site, which is the metastable adsorption site.

The magnesiation of $\mathrm{Mg}$ into $\mathrm{Sn}$ through (110) surface were studied by investigating the diffusion of $\mathrm{Mg}$ along $\mathrm{H} \rightarrow \mathrm{S} 1 \rightarrow$ $\mathrm{S} 2 \rightarrow \mathrm{S} 3 \rightarrow \mathrm{S} 4 \rightarrow \mathrm{S} 5$ diffusion path. The energetically stable sites for the intercalated $\mathrm{Mg}$ atom are the interstitial tetrahedral sites. The diffusion of $\mathrm{Mg}$ inside the $\mathrm{Sn}$ is through jumping from one tetrahedral site to an adjacent one by passing through
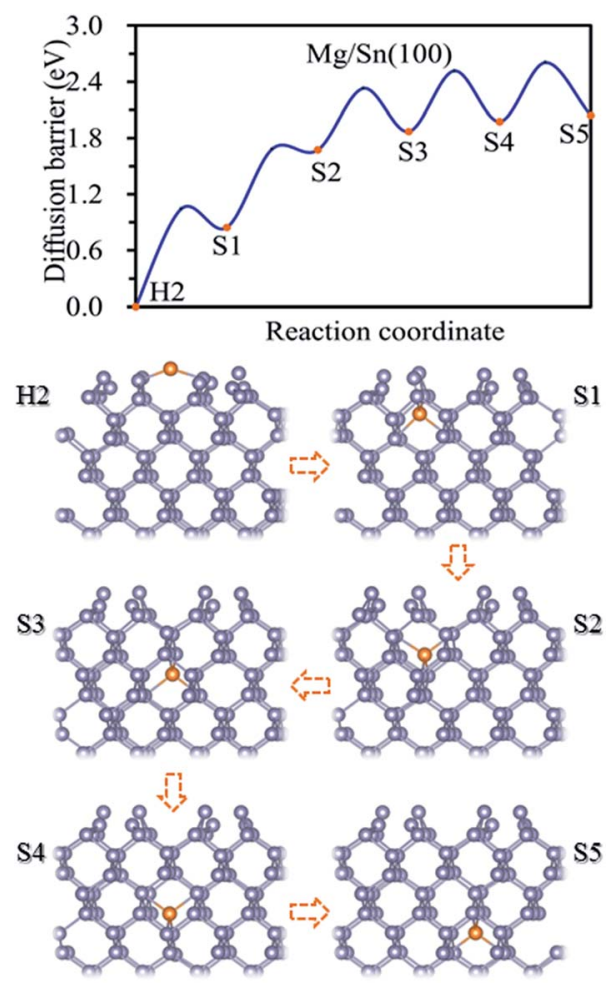

Fig. 2 Diffusion energy profile for $\mathrm{Mg}$ magnesiation into the surface and subsurface sites of $\mathrm{Sn}(100)$ and the atomic geometries at local minimum points in the profile. a hexagonal site. The diffusion energy profile and diffusion paths for $\mathrm{Mg}$ magnesiation into Sn through (110) surface are shown in Fig. 3. The diffusion energy barrier for $\mathrm{Mg}$ diffusing along the $\mathrm{H}$ $\rightarrow \mathrm{S} 1$ path is $1.58 \mathrm{eV}$, which is $0.44 \mathrm{eV}$ higher than that for $\mathrm{Mg}$ along S1 $\rightarrow$ S2 path. The diffusion energy barriers are $1.09 \mathrm{eV}$, 0.69 and $0.74 \mathrm{eV}$ for $\mathrm{Mg}$ diffuses along S2 $\rightarrow \mathrm{S} 3, \mathrm{~S} 3 \rightarrow \mathrm{S} 4$ and S4 $\rightarrow$ S5 paths, respectively. It is like the diffusion of $\mathrm{Mg}$ through the (100) surface, and the $\mathrm{H} \rightarrow \mathrm{S} 1$ path is the rate-limiting step upon $\mathrm{Mg}$ intercalated into Sn through the (110) surface.

\subsection{Adsorption and magnesiation $\mathrm{Mg}$ into $\mathrm{Sn}(111)$ surface}

Three possible adsorption sites, i.e. $\mathrm{H}, \mathrm{T} 1$ and $\mathrm{T} 2$ sites, were considered for the adsorption of $\mathrm{Mg}$ on the $\mathrm{Sn}(111)$ surface as shown in Fig. 1c. The $\mathrm{H}$ is above the center of hexagon structure composed of six non-plane Sn atoms. T1 and T2 sites are above the top of topmost and sub-high surface Sn atoms, respectively. The adsorption energies for $\mathrm{Mg}$ at $\mathrm{H}, \mathrm{T} 1$, and $\mathrm{T} 2$ sites are listed in Table 1. The $\mathrm{Mg}$ prefers to occupy the $\mathrm{H}$ site on the $\mathrm{Sn}(111)$ surface with an adsorption energy of $-1.62 \mathrm{eV}$. T2 site is less stable adsorption site, which is with an adsorption energy of $0.16 \mathrm{eV}$ higher than the $\mathrm{H}$ site. The $\mathrm{T} 1$ site is not favorable adsorption site for $\mathrm{Mg}$ with the adsorption energy of $-0.81 \mathrm{eV}$.

The magnesiation of $\mathrm{Mg}$ into $\mathrm{Sn}$ through the (111) surface was studied by considering the diffusion of $\mathrm{Mg}$ along the $\mathrm{H} \rightarrow$ $\mathrm{S} 1 \rightarrow \mathrm{S} 2 \rightarrow \mathrm{S} 3 \rightarrow \mathrm{S} 4 \rightarrow \mathrm{S} 5$ path, and the diffusion energy

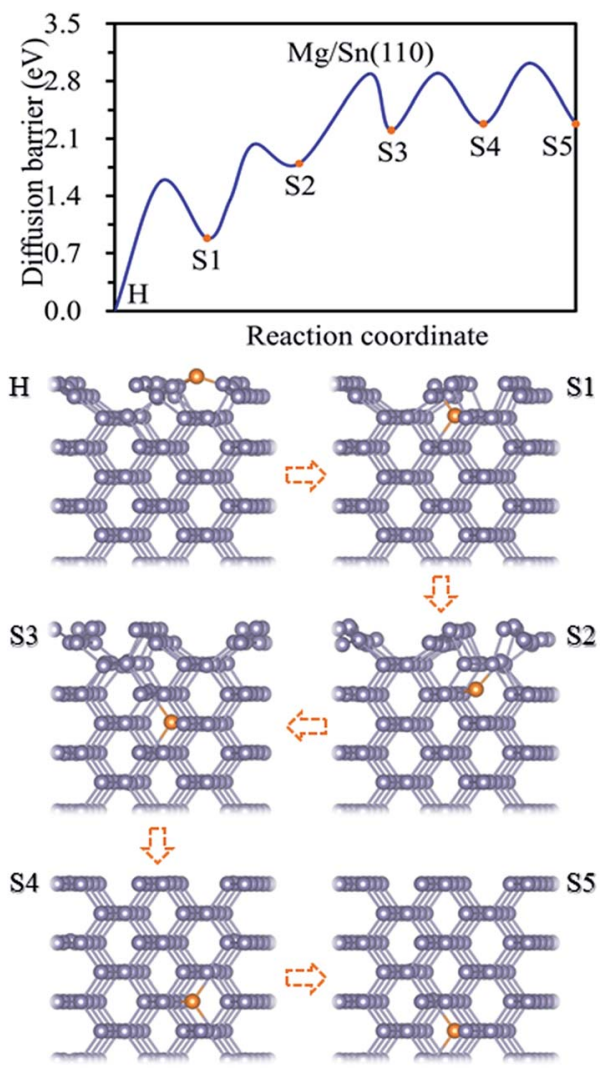

Fig. 3 Diffusion energy profile for $\mathrm{Mg}$ magnesiation into the surface and subsurface sites of $\mathrm{Sn}(110)$ and the atomic geometries at local minimum points in the profile. 
profile was shown in Fig. 4. A similar diffusion behavior was found for $\mathrm{Mg}$ magnesiation into Sn through the (111) surface as through the (100) and (110) surfaces. The diffusion energy barrier is much higher for $\mathrm{Mg}$ diffuses from the surface to the subsurface of Sn, and the diffusion energy barrier is $1.27 \mathrm{eV}$ for $\mathrm{Mg}$ along the $\mathrm{H} \rightarrow \mathrm{S} 1$ path. The diffusion barrier decreases as $\mathrm{Mg}$ diffuses inside the $\mathrm{Sn}$. The diffusion energy barriers are 0.56 and $0.54 \mathrm{eV}$ for $\mathrm{Mg}$ diffuses along $\mathrm{S} 1 \rightarrow \mathrm{S} 2$ and S3 $\rightarrow \mathrm{S} 4$ path, respectively. And they are 1.21 and 0.91 for $\mathrm{Mg}$ diffuses along S2 $\rightarrow \mathrm{S} 3$ and S4 $\rightarrow$ S5 path, respectively. So the $\mathrm{H} \rightarrow \mathrm{S} 1$ path is the rate-limiting step upon $\mathrm{Mg}$ intercalated into $\mathrm{Sn}$ through the (111) surface. It is noticed that the diffusion of $\mathrm{Mg}$ inside the $\mathrm{Sn}$ through the (111) crystal facet with small and large diffusion energy barriers repeatedly. As shown in Fig. 4, the diffusion energy barriers of $\mathrm{Mg}$ diffuses are $0.56 \mathrm{eV}$ (small) for $\mathrm{S} 1 \rightarrow \mathrm{S} 2$, $1.21 \mathrm{eV}$ (large) for S2 $\rightarrow \mathrm{S} 3,0.54 \mathrm{eV}$ (small) for S3 $\rightarrow \mathrm{S} 4$, and $0.91 \mathrm{eV}$ (large) for S4 $\rightarrow \mathrm{S} 5$. The same diffusion behavior has been observed for $\mathrm{Li}$ diffusion into $\mathrm{Si}^{17}$ and $\mathrm{Sn}^{19}$ through the (111) surface. The diffusion of $\mathrm{Mg}$ inside the $\mathrm{Sn}$ is through jumping from one tetrahedral site to an adjacent one by passing through a hexagonal site. As the hexagon is perpendicular to the (111) surface, it is easy for the relaxation of atoms, which induces a small diffusion barrier. Whereas the hexagon is parallel to the (111) surface, it is difficult for the relaxation of atoms, which induces a large diffusion energy barrier. So a small and large diffusion energy barriers repeatedly when $\mathrm{Mg}$ diffuses along the $\mathrm{S} 1 \rightarrow \mathrm{S} 2 \rightarrow \mathrm{S} 3 \rightarrow \mathrm{S} 4 \rightarrow \mathrm{S} 5$ path.
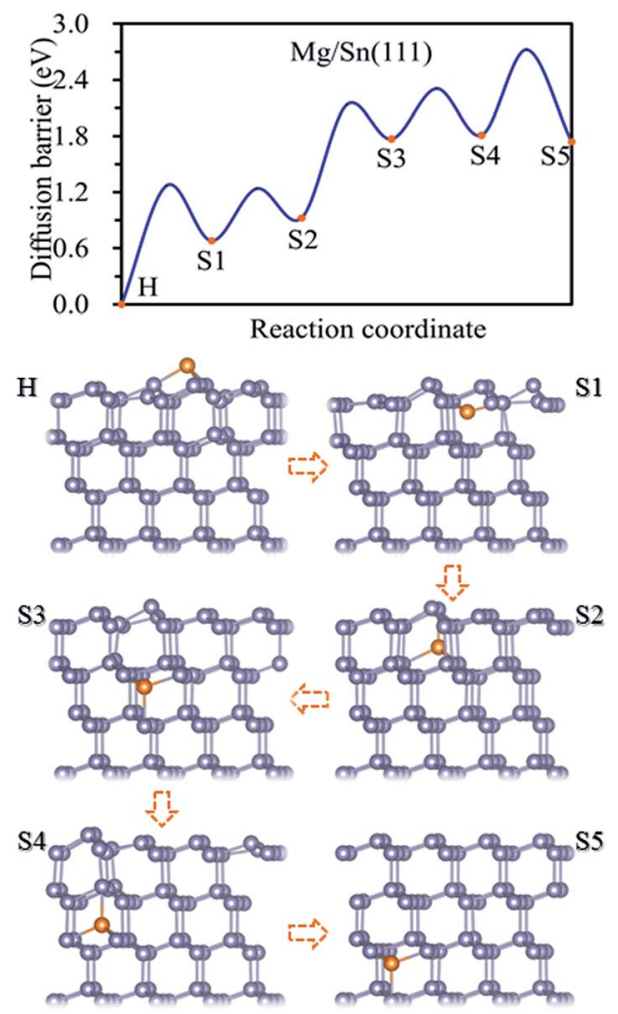

Fig. 4 Diffusion energy profile for $\mathrm{Mg}$ magnesiation into the surface and subsurface sites of $\mathrm{Sn}(111)$ and the atomic geometries at local minimum points in the profile.

\subsection{Magnesiation of $\mathrm{Mg}_{2} \mathrm{Sn}(100), \mathrm{Mg}_{2} \mathrm{Sn}(110)$ and $\mathrm{Mg}_{2} \operatorname{Sn}(111)$ surfaces}

The crystalline $\mathrm{Sn}$ transforms to crystalline $\mathrm{Mg}_{2} \mathrm{Sn}$ upon the insertion of $\mathrm{Mg}$ ions, and re-formation of crystalline $\mathrm{Sn}$ for the de-magnesiated crystalline $\mathrm{Mg}_{2} \mathrm{Sn},{ }^{12}$ we further studied the surface magnesiation behavior of (100), (110), and (111) surfaces for crystalline $\mathrm{Mg}_{2} \mathrm{Sn}$ through a vacancy mechanism. Fig. 5a shows the diffusion energy profile for the magnesiation of $\mathrm{Mg}_{2} \mathrm{Sn}(100), \mathrm{Mg}_{2} \mathrm{Sn}(110)$ and $\mathrm{Mg}_{2} \mathrm{Sn}(111)$ surfaces, and the corresponding diffusion paths $(1 \rightarrow 2 \rightarrow 3 \rightarrow 4 \rightarrow 5$ path) are shown in Fig. 5b, c, and d, respectively. $\mathrm{Mg}$ atom migrates from the $\mathrm{Mg}$ layer to the adjacent $\mathrm{Mg}$ layer by passing through an interstitial site located in the Sn layer through the $\mathrm{Mg}_{2} \mathrm{Sn}(100)$ surface. And the diffusion barriers are 1.15, 0.38, 0.48, and $0.47 \mathrm{eV}$ for $\mathrm{Mg}$ diffuses from the outmost surface to the inside $\mathrm{Mg}$ layer along the $1 \rightarrow 2 \rightarrow 3 \rightarrow 4 \rightarrow 5$ diffusion path through the $\mathrm{Mg}_{2} \mathrm{Sn}(100)$ surface. As $\mathrm{Mg}$ diffuses from one $\mathrm{Mg}-\mathrm{Sn}$ layer to the adjacent $\mathrm{Mg}-\mathrm{Sn}$ layer through $\mathrm{Mg}_{2} \mathrm{Sn}(110)$ surface, it needs to overcome energy barriers of $0.75,0.42,0.44$, and $0.34 \mathrm{eV}$. The diffusion energy barriers are $0.20,0.25,0.36$, and $0.42 \mathrm{eV}$ for $\mathrm{Mg}$ diffuses into $\mathrm{Mg}_{2} \mathrm{Sn}$ through (111) surface. It can be seen from Fig. 5a that the surface diffusion is a rate-limiting step upon $\mathrm{Mg}$ intercalated into $\mathrm{Mg}_{2} \mathrm{Sn}$ through (100) and (110) surfaces, whereas the surface magnesiation of $\mathrm{Mg}_{2} \mathrm{Sn}(111)$ surface is easier than (100) and (110) surfaces.

From the above results, it can be seen that the diffusion energy barrier is higher for $\mathrm{Mg}$ diffuses from the surface to subsurface compared with the inside diffusion as $\mathrm{Mg}$ intercalated into $\mathrm{Sn}$ though (100), (110) and (111) surfaces and into $\mathrm{Mg}_{2} \mathrm{Sn}$ through (100) and (110) surfaces. When $\mathrm{Mg}$ was intercalated into the Sn, the diffusion process from the surface to the subsurface is the rate-limiting step. Comparing the diffusion behavior of $\mathrm{Mg}$ into
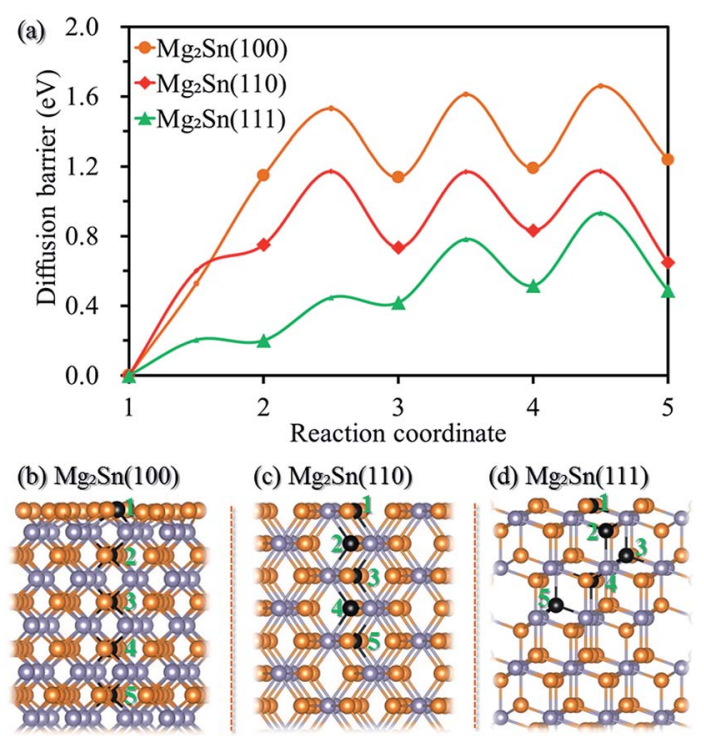

Fig. 5 (a) Diffusion energy profile for $\mathrm{Mg}$ magnesiation into $\mathrm{Mg}_{2} \mathrm{Sn}$ though (100), (110) and (111) surfaces, along with the schematic diffusion path through (b) $\mathrm{Mg}_{2} \mathrm{Sn}(100)$, (c) $\mathrm{Mg}_{2} \mathrm{Sn}(110)$, and (d) $\mathrm{Mg}_{2} \mathrm{Sn}(111)$ surfaces. The orange and gray balls represent $\mathrm{Mg}$ atoms and $\mathrm{Sn}$ atoms, respectively. The black balls represent the Mg-vacancy. 
Sn through (100), (110) and (111) surfaces, the one from the (100) surface is easier than (110) and (111) surfaces. The intercalation of $\mathrm{Mg}$ into $\mathrm{Mg}_{2} \mathrm{Sn}$ through (111) surface is easier than through (100) and (110) surfaces. The surface magnesiation should be considered for Sn as anode for MIBs, especially when anode materials are decreased to nanoscale, and the surface electrochemical reaction is a key factor that affects battery performance. Surface modification such as metal doping ${ }^{30}$ could be used to reduce the surface magnesiation barrier.

\section{Conclusion}

In conclusion, $\mathrm{Mg}$ magnesiation into $\alpha$-Sn and $\mathrm{Mg}_{2} \mathrm{Sn}$ through (100), (110) and (111) surfaces was investigated using density functional theory. The diffusion energies barriers are in the range 0.63-1.05, 0.68-1.58 and 0.54-1.27 eV for $\mathrm{Mg}$ diffuses in Sn along the $<100>,<110>$ and $<111>$ directions, respectively. $\mathrm{Mg}$ diffuses faster along the $<100>$ direction than along $<110>$ and $<111>$ directions. The diffusion energy barriers are 1.05, 1.58 and $1.27 \mathrm{eV}$ for $\mathrm{Mg}$ diffuses from the surface to subsurface by penetrating $\operatorname{Sn}(100), \operatorname{Sn}(110)$ and $\operatorname{Sn}(111)$ surfaces, respectively, which are larger than the value of $\mathrm{Mg}$ diffuses inside $\mathrm{Sn}$. The surface magnesiation is also the rate-limiting step upon $\mathrm{Mg}$ intercalated into $\mathrm{Mg}_{2} \mathrm{Sn}$ though (100) and (110) surfaces. The $\mathrm{Mg}$ diffusion from the surface to subsurface becomes the ratelimiting step for Sn used as anode for MIBs. Surface modification to improve the magnesiation behavior should be considered for Sn as anode for MIBs, especially anode materials are decreased to nanoscale.

\section{Conflicts of interest}

There are no conflicts of interest to declare.

\section{Acknowledgements}

This work was financially supported by the National Natural Science Foundation of China (11474047) and the Fundamental Research Funds for the Central Universities (ZYGX2016J202). This work was carried out at National Supercomputer Center in Tianjin, and the calculations were performed on TianHe-1(A).

\section{References}

1 D. Aurbach, Y. Gofer, A. Schechter, O. Chusid, H. Gizbar, Y. Cohen, M. Moshkovich and R. Turgeman, J. Power Sources, 2001, 97, 269-273.

2 Y. G. D. Aurbach, Z. Lu, A. Schechter, O. Chusid, H. Gizbar, Y. Cohen, V. Ashkenazi, M. Moshkovich, R. Turgeman and E. Levi, J. Power Sources, 2001, 97, 28-32.

3 M. M. Huie, D. C. Bock, E. S. Takeuchi, A. C. Marschilok and K. J. Takeuchi, Coord. Chem. Rev., 2015, 287, 15-27.
4 J. S. Kim, W. S. Chang, R. H. Kim, D. Y. Kim, D. W. Han, K. H. Lee, S. S. Lee and S. G. Doo, J. Power Sources, 2015, 273, 210-215.

5 E. Levi, Y. Gofer and D. Aurbach, Chem. Mater., 2010, 22, 860-868.

6 H. D. Yoo, I. Shterenberg, Y. Gofer, G. Gershinsky, N. Pour and D. Aurbach, Energy Environ. Sci., 2013, 6, 2265-2279.

7 S. Rasul, S. Suzuki, S. Yamaguchi and M. Miyayama, Electrochim. Acta, 2013, 110, 247-252.

8 Y. L. Liang, R. J. Feng, S. Q. Yang, H. Ma, J. Liang and J. Chen, Adv. Mater., 2011, 23, 640-644.

9 C. Ling, R. Zhang, T. S. Arthur and F. Mizuno, Chem. Mater., 2015, 27, 5799-5807.

10 W. Jin, Z. Wang and Y. Q. Fu, J. Mater. Sci., 2016, 51, 7355-7360.

11 D. L. Aurbach, Z. Lu, A. Schechter, Y. Gofer, H. Gizbar, R. Turgeman, Y. Cohen, M. Moshkovich and E. Levi, Nature, 2000, 407, 724-727.

12 N. Singh, T. S. Arthur, C. Ling, M. Matsui and F. Mizuno, Chem. Commun., 2013, 49, 149-151.

13 Z. Wang, Q. Su, J. Shi, H. Deng, G. Q. Yin, J. Guan, M. P. Wu, Y. L. Zhou, H. L. Lou and Y. Q. Fu, ACS Appl. Mater. Interfaces, 2014, 6, 6786-6789.

14 Y. H. Xu, Q. Liu, Y. J. Zhu, Y. H. Liu, A. Langrock, M. R. Zachariah and C. S. Wang, Nano Lett., 2013, 13, 470-474.

15 J. Chen and F. Y. Cheng, Acc. Chem. Res., 2009, 42, 713-723.

16 O. I. Malyi, T. L. Tan and S. Manzhos, J. Power Sources, 2013, 233, 341-345.

17 S. C. Jung and Y. K. Han, Phys. Chem. Chem. Phys., 2011, 13, 21282-21287.

18 P. Kaghazchi, J. Chem. Phys., 2013, 138, 054706.

19 S. C. Jung and Y. K. Han, Phys. Chem. Chem. Phys., 2013, 15, 13586-13592.

20 T. Slusarski, B. Brzostowski, D. Tomecka and G. Kamieniarz, Acta Phys. Pol., A, 2010, 118, 967-968.

21 G. Kresse and J. Furthmuller, Comput. Mater. Sci., 1996, 6, 15-50.

22 G. Kresse and D. Joubert, Phys. Rev. B: Condens. Matter Mater. Phys., 1999, 59, 1758-1775.

23 N. Troullier and J. L. Martins, Phys. Rev. B: Condens. Matter Mater. Phys., 1991, 43, 8861-8869.

24 C. Kittel, Introduction to Solid State Physics, New York, 2005.

25 V. Fiorentini and M. Methfessel, J. Phys.: Condens. Matter, 1996, 8, 6525-6529.

26 B. Peng, F. Cheng, Z. Tao and J. Chen, J. Chem. Phys., 2010, 133, 034701.

27 J. Neugebauer and M. Scheffler, Phys. Rev. B: Condens. Matter Mater. Phys., 1992, 46, 16067-16080.

28 Y. Morikawa, K. Kobayashi and K. Terakura, Surf. Sci., 1993, 283, 377-382.

29 T. L. Chan and J. R. Chelikowsky, Nano Lett., 2010, 10, 821-825. 30 B. R. Long, M. K. Y. Chan, J. P. Greeley and A. A. Gewirth, J. Phys. Chem. C, 2011, 115, 18916-18921. 